Article

\title{
Investigation of Mineral-Processing Wastewater Recycling Processes: A Pilot Study
}

\author{
Jin Hee Park ${ }^{1}$, Young-Soo Han ${ }^{2}$ and Sang-Woo Ji ${ }^{2, *}$ \\ 1 Department of Environmental \& Biological Chemistry, Chungbuk National University, Cheongju, \\ Chungbuk 28644, Korea; pjinh@chungbuk.ac.kr \\ 2 Geologic Environment Division, Korea Institute of Geoscience and Mineral Resources, 124 Gwahak-ro, \\ Yuseong-gu, Daejeon 34132, Korea; yshan@kigam.re.kr \\ * Correspondence: swji@kigam.re.kr; Tel.: +82-42-868-3414
}

Received: 30 July 2018; Accepted: 25 August 2018; Published: 29 August 2018

check for updates

\begin{abstract}
Mineral processing requires large amounts of water, but, often in the remote locations of many mines, sufficient fresh water frequently cannot be supplied. Therefore, recycling of water is important in mineral processing and enhancing the efficiency of the liquid-solid separation and dewatering steps in mineral processing wastewater treatment is critical. The objectives of the study were to evaluate the effect of anionic flocculant dosage and sludge recycling (SR) on solid removal and sludge dewaterability. Different combinations of the flocculant dosage with and without SR were applied in a mineral-processing wastewater treatment pilot plant. Increasing the amount of flocculant dose of $1.1 \% v / v$ (flocculant solution to wastewater) did not significantly decrease the turbidity of the treated water, while the combination of a flocculant with SR increased the zeta potential. Increasing flocculant dose adversely affected dewaterability, although the dewaterability of the $0.6 \% v / v$ flocculant-treated sludge significantly increased after aging of the sludge. Sludge recycling was effective for increasing the dewaterability, and a flocculant dose of $1.1 \% v / v$ with SR led to formation of large flocs that were stable during aging and sonication.
\end{abstract}

Keywords: dewaterability; flocculation; specific resistance to filtration; sludge; water

\section{Introduction}

Mineral processing separates valuable minerals from ores, and includes the use and transport of water throughout the treatment stages. Flotation, a common and valuable process for mineral separation, is conducted with water containing $25-35 \mathrm{wt} \%$ solids and consumes $1.9-3.0 \mathrm{~m}^{3}$ of water per ton of ore processed [1]. Mineral processing requires large volumes of water, but the availability of water in the areas where minerals are processed is generally limited. Therefore, reducing water consumption and recycling water on site is critical for mineral processing.

Mineral-processing wastewater includes pollutants such as solid particles, heavy metals, and residual chemical reagents [2]. During the treatment of mineral-processing wastewater, various techniques are applied to remove the pollutants. Coagulation and flocculation can be used for solid/liquid separation. Coagulation-flocculation process is regarded as one of the most important and widely used treatment processes of industrial wastewater [3] and raw water [4] due to its simplicity and effectiveness. Coagulation involves neutralization of the surface charge on solid particles by addition of ionic chemicals, adsorption by counter-ion, and electrostatic screening. Flocculation refers to bridging together of particles using organic polymers that adsorb to the particles [5]. Because mineral-processing wastewater contains suspended solids, coagulation and flocculation are important steps in treating the water. The coagulation and flocculation processes not only work to remove suspended solids, but also enhance the removal of heavy metals in treated water [6]. However, the residual chemical 
reagents remaining in wastewater or on the solids can be contaminants. Therefore, an optimal amount of chemical reagent should be added in the wastewater treatment process. Sludge recycling to the flocculation process is beneficial for solid settling and subsequent dewatering in part due to using residual coagulation and flocculation chemicals in the sludge [7]. It is also known to enhance the efficiency of turbidity reduction in low-turbidity raw water [8].

In mineral-processing wastewater treatment, sludge settling and dewatering is critical for recycling of water, which affects the efficiency and cost of mineral processing and wastewater treatment [9]. Therefore, this study was focused on enhancement of solid/liquid separation in the recycling of mineral-processing wastewater. Laboratory experiments to optimize the dosage of the flocculant used to reduce the turbidity of recycled wastewater showed that increasing the flocculant dosage did not reduce turbidity [10]. However, laboratory scale results are not always repeated at pilot and full scale, so a pilot scale study was required. The objective of this study was to evaluate the most effective process for treating mineral-processing wastewater, in particular, the dose of flocculant needed at pilot scale and the benefits of sludge recycling.

\section{Materials and Methods}

\subsection{Mineral-Processing Wastewater Treatment Pilot System}

The mineral-processing wastewater pilot system was constructed at a molybdenum mine in Jecheon, Republic of Korea. The pilot system comprised a particle separation unit, a wastewater tank $(1.2 \times 1.2 \times 1.2 \mathrm{~m})$, a quantitative inflow regulation tank $(\mathrm{W} 0.4 \times \mathrm{L} 0.8 \times \mathrm{H} 0.4 \mathrm{~m})$, a reagent tank $\left(1 \mathrm{~m}^{3}\right)$, a static mixer (W0.42 $\left.\times \mathrm{L} 1.4 \times \mathrm{H} 0.4 \mathrm{~m}\right)$, and a settling tank $(\varnothing 1.8 \mathrm{~m} \times \mathrm{H} 2.4 \mathrm{~m})$ (Figure 1). Large particles in the mineral-processing wastewater were separated using a particle size separator and a cyclone, and the wastewater was then transported to a wastewater tank. From this tank, wastewater was pumped by a $0.37 \mathrm{~kW}, 0.2 \mathrm{~m}^{3} / \mathrm{min}$ pump to a static mixer. The required dose of flocculant was supplied to the static mixer using a static pump. The dose of flocculant was calculated based on the amount of flocculant added per the amount of sludge treated. The flocculant was composed of $35 \%$ sodium 2-propenoate 2-propenamide polymer, $35 \%$ water, $2.5 \%$ polyoxyethylene lauryl ether, $25 \%$ aliphatic/cyclo aliphatic hydrocarbon, and 2.5\% sorbitan monooleate (anionic polymer flocculant, SNF Korea, Seoul, Korea). After flocculation in a reaction tank, the slurry was transported to a settling tank having a $3 \mathrm{~h}$ liquid retention time. After settlement for $3 \mathrm{~h}$, the slurry was pumped out for dewaterability test.

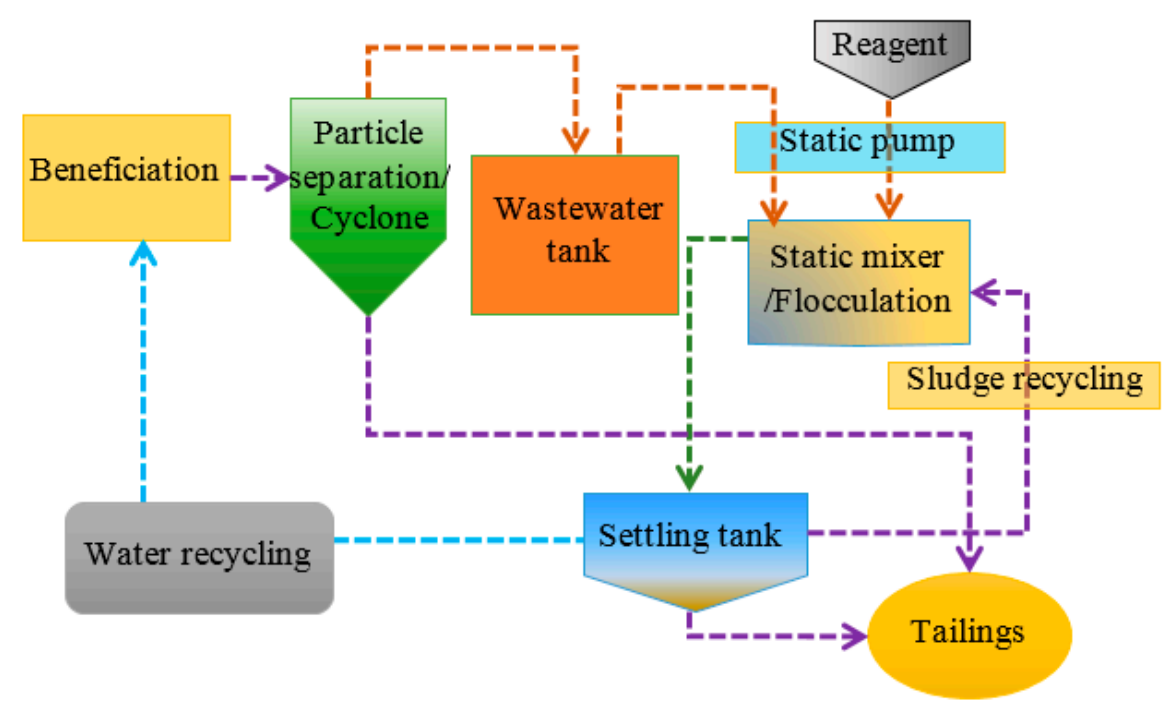

Figure 1. Cont. 

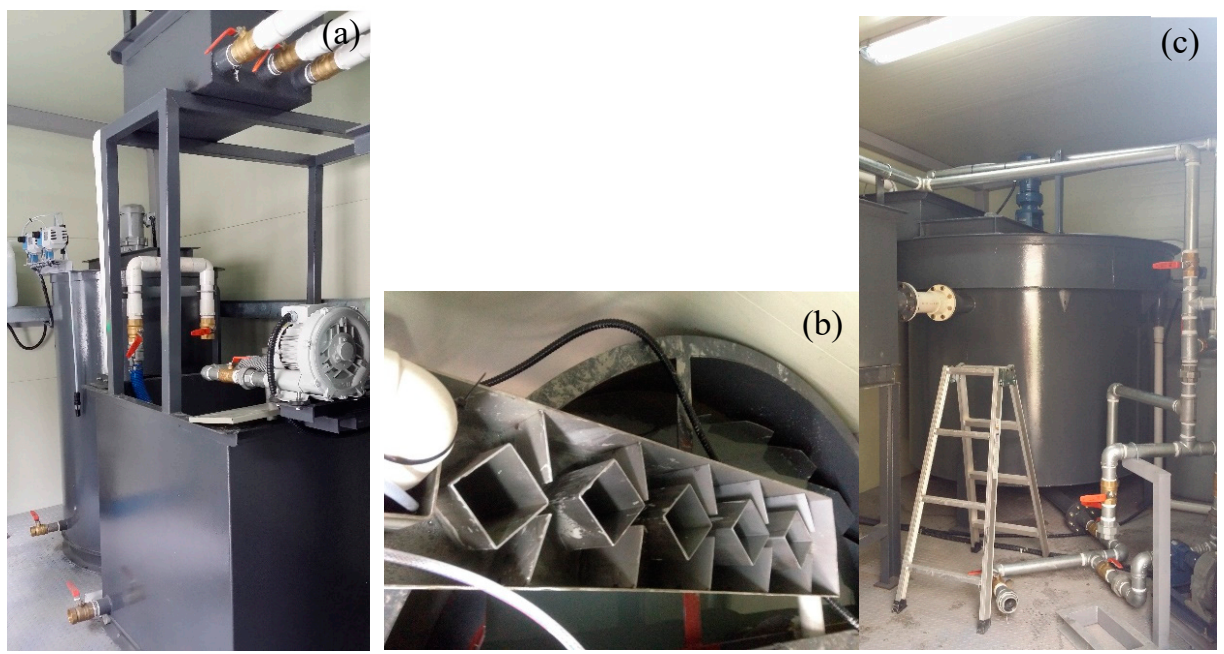

Figure 1. Schematic of the mineral-processing wastewater treatment pilot system (top) and photos of (a) Wastewater tank and quantitative inflow regulation tank, (b) Static mixer, and (c) Settling tank.

\subsection{Characterization of the Mineral-Processing Wastewater}

Mineral-processing wastewater from the molybdenum mine processing facility was sampled and the $\mathrm{pH}$ and electrical conductivity (EC) were measured using a portable $\mathrm{pH}$ and $\mathrm{EC}$ meter (HQ40d, HACH, Loveland, CO, USA). Turbidity of the wastewater exceeded 800 NTU and could not be measured without a dilution step. Cations and anions in the wastewater were analyzed using inductively coupled plasma atomic emission spectroscopy (Ultima2, HORIBA, Kyoto, Japan) and ion chromatography (881 compact IC Pro, Metrohm, Herisau, Switzerland), respectively, after filtration $(<0.45 \mu \mathrm{m})$.

\subsection{Wastewater Treatment Operating Conditions}

The mineral-processing wastewater was not acidic and did not contain high amounts of heavy metals; so solid/liquid separation was the major issue in the treatment of the mineral-processing wastewater (Table 1). To optimize the solid/liquid separation and dewatering efficiency, the flocculant dosage ( $v / v \%$ flocculant/wastewater) was adjusted to $0.0 \%, 0.6 \%, 0.7 \%, 0.8 \%$, or $1.1 \%$ and the treated water and sludge under each condition were tested to obtain values of the water quality parameters and dewatering efficiency, respectively. The flocculant was mixed with the mineral-processing wastewater at $90 \mathrm{rpm}$. To test the effect of the sludge recycling, some sludge was transported to a static mixer with pump $(20 \mathrm{~L} / \mathrm{min} \times 1 \mathrm{HP})$ in cases with pilot batches with $0.7 \%$ and $1.1 \%$ flocculant dosage.

Table 1. Properties of the mineral-processing wastewater.

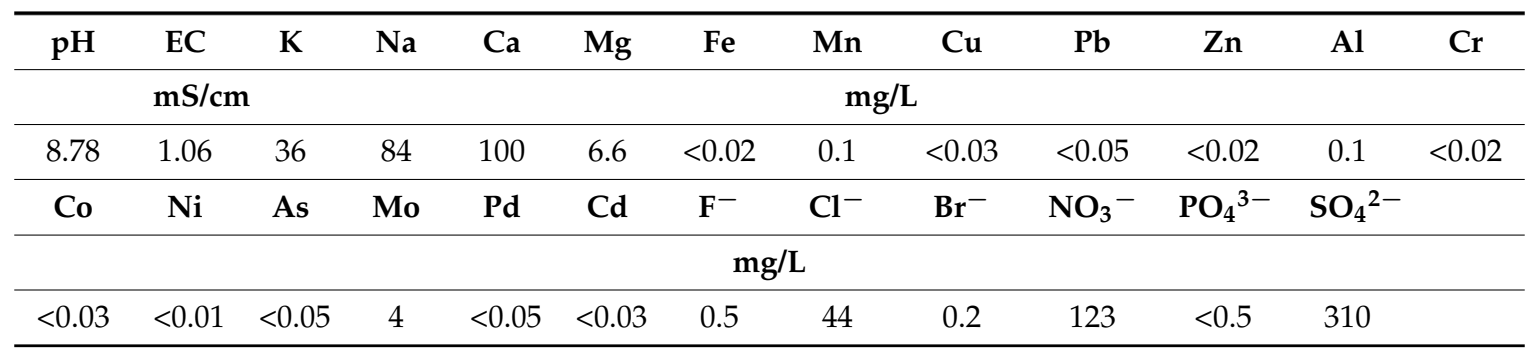

\subsection{Characterization of Treated Water and Sludge}

Supernatant was collected from the settling tank; and $\mathrm{pH}, \mathrm{EC}$, and turbidity were measured on site. The $\mathrm{pH}$ and electrical conductivity (EC) were analyzed using a portable $\mathrm{pH}$ and $\mathrm{EC}$ meter and turbidity 
was measured using a portable turbidity meter $(2100 \mathrm{Q}, \mathrm{HACH})$. The zeta potential of the treated water was analyzed using a zeta potential analyzer (Zetasizer, Malvern, UK). Sludge samples were collected in two $2 \mathrm{~L}$ polyethylene bottles using a sludge pump after $3 \mathrm{~h}$ of settlement in a settling tank. One bottle was analyzed soon after sampling and the other bottle was stored for two months to test the stability of the flocs formed. Because dewatering requires more time than the wastewater treatment process, and because the capacity to store sludge from the settling tank is limited in full scale plant, sometimes the settled sludge could not be dewatered immediately after wastewater treatment. If sludge could not be transported to a dewatering facility, it was transported to a storage tank and stored there for several months in full scale plant. Therefore, the dewaterability of the stored sludge was tested. Sludge samples were well mixed, settled for $21 \mathrm{~h}$, and supernatant was decanted. The remaining sludge was analyzed for dewaterability. The water content was analyzed by measuring the sludge weight before and after drying of the sample in an oven at $90^{\circ} \mathrm{C}$ for $24 \mathrm{~h}$. The floc size of the sludge was determined using a laser diffraction particle size analyzer (HELOS, Sympatec, Clausthal-Zellerfeld, Germany). The particle size distribution of the sludge was analyzed before and after sonication for $3 \mathrm{~min}$, to evaluate the stability of the flocs.

The specific resistance to filtration (SRF), which is used to measure sludge dewatering properties, was determined by vacuum filtering sludge and measuring the filter volume and time for filtration [11]. Specific resistance was calculated using Equation (1). A higher SRF value indicates sludge that is more difficult to dewater.

$$
\mathrm{r}=\frac{2 b P A^{2}}{\mu C}
$$

r: specific resistance $(\mathrm{m} / \mathrm{kg})$

$b$ : slope of the filtrate volume vs. time/filtrate volume curve

$\mu$ : filtrate viscosity $\left(\mathrm{N} \cdot \mathrm{s} / \mathrm{m}^{2}\right)$

C: concentration of slurry $\left(\mathrm{kg} / \mathrm{m}^{3}\right)$

$A$ : filter area $\left(\mathrm{m}^{2}\right)$

$P$ : applied pressure $\left(\mathrm{N} / \mathrm{m}^{2}\right)$

$V$ : volume of filtrate $\left(\mathrm{m}^{3}\right)$

Sludge samples were analyzed after two months of storage for viscosity, moisture content, particle size, and SRF according to the procedure described above.

\section{Results and Discussion}

\subsection{Treated Water Quality}

There are no standards for wastewater recycled after mineral processing. Instead, the treated water quality was evaluated based on the discharge water and stream water quality standard, Republic of Korea [12]. Although the $\mathrm{pH}$ of the discharge water is not regulated by law, the acceptable $\mathrm{pH}$ range for stream water is between $\mathrm{pH} 6.5$ and 8.5. The $\mathrm{pH}$ of the treated water slightly increased compared to that of the mineral-processing wastewater, and was slightly higher than the standard for stream water. However, increasing amount of flocculant addition slightly decreased the $\mathrm{pH}$ and the $\mathrm{pH}$ of the water treated with $1.1 \% \mathrm{SR}$ was in a $\mathrm{pH}$ range that was acceptable. The carboxylate groups of the anionic flocculant are ionized when sludge $\mathrm{pH}$ is high, which might lead to decreased $\mathrm{pH}$ with $1.1 \%$ flocculant addition.

Toxic metal concentrations in the untreated wastewater were below the limit of detection used. Therefore, the study was focused on the removal of solid particles (Table 1). The removal of solid particles and the stability of the particles in suspension were measured by turbidity and zeta potential, respectively. Increasing the amount of flocculant and performing sludge recycling, appeared to slightly reduce the turbidity of the treated water indicating that increasing amount of flocculant addition enhanced floc formation; although the turbidity of the treated water was not significantly different 
between treatments (Table 2). Dash et al. [13] reported that the settling rate of iron ore tailings increased with increasing flocculant dosage up to the maximum adsorption value of the flocculant on the tailings.

Table 2. Parameters of pilot-scale treated water with varying flocculant and sludge recycling. Means with different letters within same measured parameter indicates that differences are significant based on Duncan's multiple range test $(p<0.05)$.

\begin{tabular}{cccccc}
\hline Flocculant dosage & $0.6 \%$ & $0.7 \% \mathrm{SR}^{*}$ & $0.8 \%$ & $1.1 \%$ & $1.1 \% \mathrm{SR}^{*}$ \\
\hline Turbidity $(\mathrm{NTU})$ & $71 \pm 12 \mathrm{a}$ & $76 \pm 8 \mathrm{a}$ & $71 \pm 3 \mathrm{a}$ & $68 \pm 4 \mathrm{a}$ & $57 \pm 6 \mathrm{a}$ \\
\hline Zeta potential $(\mathrm{mV})$ & $-16.8 \pm 0.8 \mathrm{~b}$ & $-16.1 \pm 1.1 \mathrm{~b}$ & $-19.4 \pm 0.8 \mathrm{c}$ & $-18.7 \pm 1.3 \mathrm{c}$ & $-9.09 \pm 0.2 \mathrm{a}$ \\
\hline $\mathrm{pH}$ & 8.84 & 8.77 & 8.79 & 8.71 & 8.08 \\
\hline $\mathrm{EC}(\mathrm{mS} / \mathrm{cm})$ & 1.17 & 1.12 & 1.10 & 1.10 & 1.10 \\
\hline \multicolumn{5}{c}{${ }^{*}$ SR indicates sludge recycling. }
\end{tabular}

The zeta potential of the water treated with $1.1 \%$ flocculant with sludge recycling $(1.1 \%$ SR) was close to zero while the zeta potentials for treatment with only flocculant at $0.8 \%$ and $1.1 \%$, were the farthest from zero $(-19.4 \mathrm{mV}$ to $-18.7 \mathrm{mV})$. The zeta potential is an indication of repulsive interaction among colloidal particles [14]. Flocculation without sludge recycling ( $0.8 \%$ and $1.1 \%$ flocculant dose) resulted in suspended solids in the treated water being more stable in suspension than in the case of $0.7 \%$ flocculant with sludge recycling $(0.7 \% \mathrm{SR})$ (Table 2$)$. A zeta potential between -10 and $+10 \mathrm{mV}$ is regarded as approximately neutral, while zeta potentials greater than $+30 \mathrm{mV}$ and less than $-30 \mathrm{mV}$ are stable [15]. Therefore, $1.1 \%$ of flocculant with sludge recycling $(1.1 \% \mathrm{SR})$ was the most effective water treatment according to the turbidity and zeta potential of the treated water. Charge neutralization and bridging flocculation are the main mechanisms involved in particle flocculation among differently charged particles and flocculant. It is generally found that the turbidity is lowest (and the flocculant dose is optimal); when the zeta potential is close to zero [16].

\subsection{Dewaterability of the Sludge}

Sludge dewaterability after wastewater treatment was evaluated by SRF, moisture content, and viscosity of the sludge. Dewaterability as measured by SRF was not directly related to viscosity and moisture content of the sludge. Dewaterability was slightly improved with sludge recycling. However, without sludge recycling, the SRF increased and was highest with a dosage of $0.8 \%$ flocculant (Figure 2). This indicates that increasing the amount of flocculant adversely affected dewaterability while the adverse effect was compensated by enhancement from the sludge recycling. Although the sludge recycling compensated for the adverse effect of high flocculant dosage, increasing the flocculant dosage for the combined treatment (flocculant and sludge recycling) did not lead to better dewaterability. Therefore, the combined treatment of $0.7 \%$ flocculant with sludge recycling $(0.7 \% \mathrm{SR})$ was the most effective option in terms of dewaterability. 


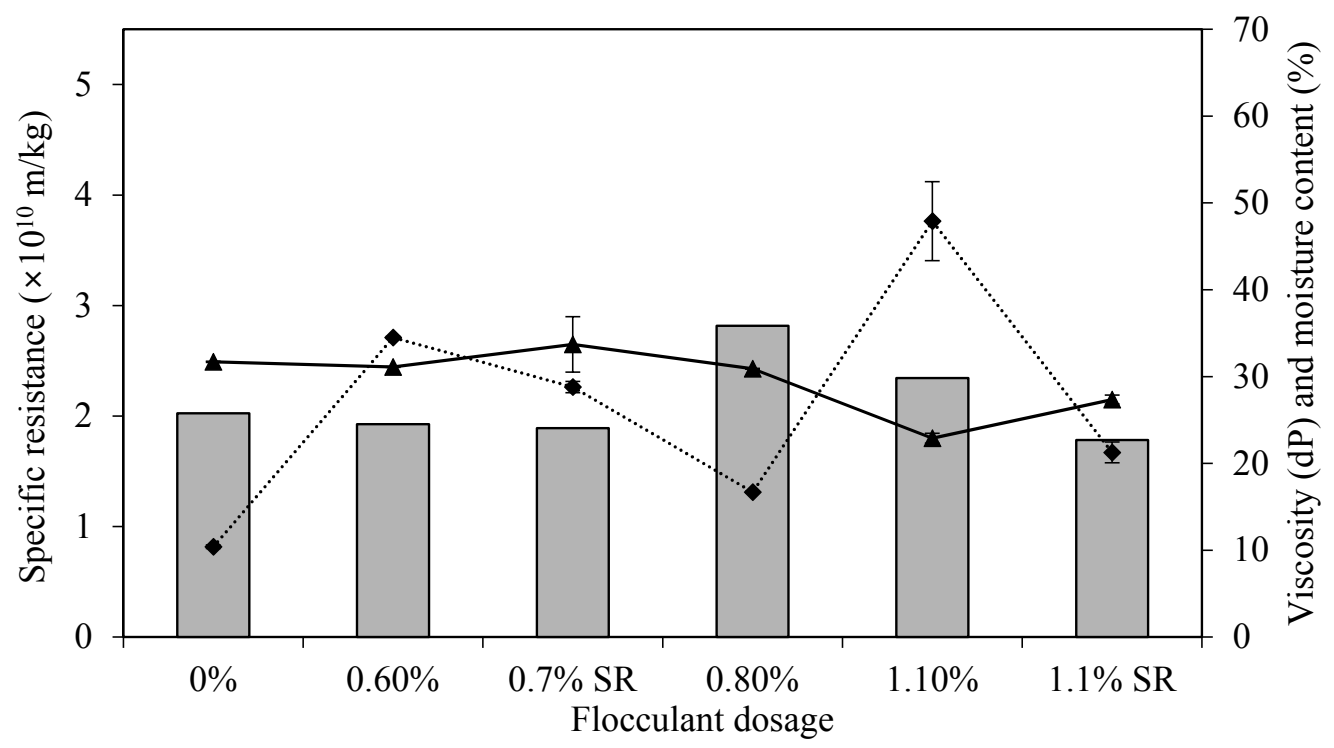

$\square$ Specific resistance $\cdots . . \cdot$ Viscosity $(\mathrm{dP}) \longrightarrow$ Moisture content

Figure 2. Specific resistance, viscosity, and moisture content of the sludge collected after wastewater treatment with different dosage of flocculant and sludge recycling.

The moisture content decreased with addition of $1.1 \%$ flocculant, which meant lower bound-water content and thus tightly packed sludge flocs [17]. However, the bound water may not be related to dewaterability and SRF will be influenced not by the bound water, but by the free water. In addition, SRF may be related to the micro-structure of the sludge flocs [18].

The viscosity of the activated sludge is known to reflect the magnitude of particle interaction in a suspension and to be correlated to dewaterability [18]. However, the viscosity of the mineral-processing sludge was not related to SRF, which was used to assess the dewaterability of the sludge in this study. The different characteristics of mineral processing sludge in comparison with other sludge might be responsible for the lack of relationship between viscosity and dewaterability in this study. Other experiments on the relationship between sludge viscosity and dewaterability were tested mostly with activated sludge, in which the viscosity changes induced by microbes are important factors influencing dewaterability $[19,20]$. The highest viscosity of the sludge treated with $1.1 \%$ flocculant might be related to the lowest moisture content, which was caused by sedimentation and compression of the sludge (Figure 2). Improving dewaterability is important because it reduces the cost of subsequent treatment and disposal [21]. In the studied mineral-processing facility, annual operation and maintenance cost comprises $22.3 \%$ electricity, $15.7 \%$ flocculant, and $60 \%$ filter press cost (personal communication). Therefore, reducing the use of flocculant and improving dewaterability will save significant cost for wastewater treatment.

\subsection{Stability of the Flocculent}

The stability of the flocs was evaluated by analyzing the moisture content, viscosity, and SRF after storage of the sludge for two months. Overall, the SRF increased in all treatments and the SRF of sludge treated with $0.6 \%$ flocculant was the highest (Figure 3). This can be attributed to compaction of the floc with storage. Therefore, in terms of long-term stability of sludge, the treatment with $0.6 \%$ flocculant was not effective. Liss et al. [22] reported that flocs of greater age were less hydrated and physically more stable than flocs of lesser age. Disruption of some flocs after aging may release solid particles, which block pores and lead to increased SRF. Storage of the sludge does not affect its moisture content and consequently it is rational that the increase in the SRF was not caused by changes in moisture content. 


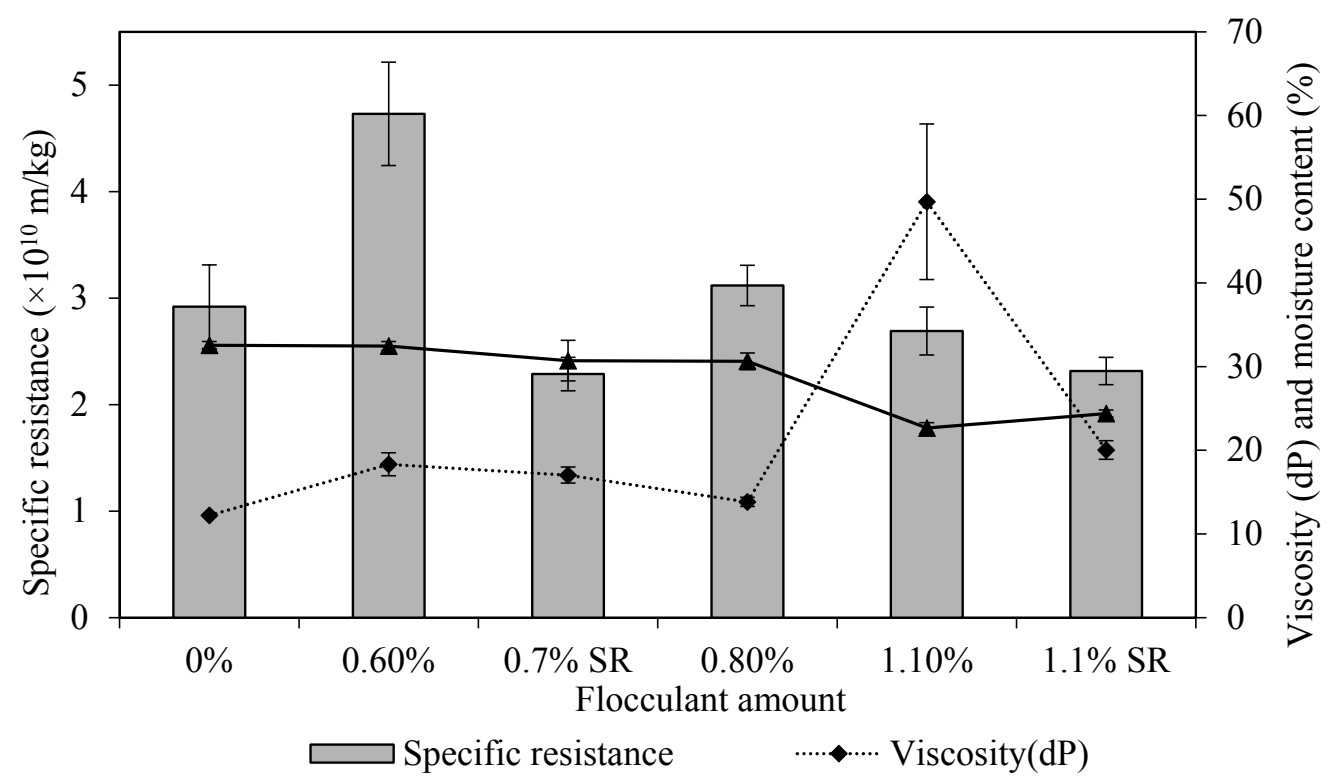

Figure 3. Specific resistance, viscosity, and moisture content of the sludge measured two months after wastewater treatment with different dosage of flocculant and sludge recycling.

Viscosity of the sample treated with $0.6 \%$ flocculant and the sample treated with $0.7 \%$ flocculant with sludge recycling $(0.7 \%$ SR), significantly decreased after two months of storage. Generally, sludge with high viscosity presents low dewaterability. However, in this study, although viscosity decreased, the SRF increased in sludge treated with $0.6 \%$ flocculant. The decreased viscosity could be related to the breakdown of aggregates. Changes in the particle size distribution caused by the breakdown of aggregates might have resulted in changes in the mineral sludge rheology. The behavior shown in the $0.6 \%$ flocculant treatment is not consistent with the generally reported relationships between viscosity and SRF in aged sludge. Pollice et al. [23] showed that sludge viscosity increased with increasing SRF and with transient sludge growth, which is related to reduction in the suspended solid content. Li and Yang [17] reported that aging might lead to reduced viscosity and that the viscosity was stabilized over all treatments because the adsorption of loosely bound flocculants increased with aging. However, they also reported that a high level of loosely bound extracellular polymeric substances could increase viscosity.

\subsection{Particle Size Distribution of the Sludge}

With increase in the flocculant dosage from 0.6 to $0.8 \%$, the particle size distribution of the sludge collected soon after wastewater treatment, shifted toward the coarser fraction (Figure 4a). However, addition of a small amount of flocculant seemed to prevent floc formation because particles were smaller when $0.6-0.8 \%$ flocculant was added, than when flocculant was not used. The particle size distribution of the sludge after treatment with $1.1 \%$ flocculant with sludge recycling $(1.1 \% \mathrm{SR})$ was similar to that of sludge to which no flocculant was added. Sludge recycling was not effective for the formation of large flocs while addition of $1.1 \%$ flocculant without sludge recycling significantly enhanced formation of large flocs. Particles in the range 70-100 $\mu \mathrm{m}$ increased with addition of $1.1 \%$ flocculant.

Sonication is used to disrupt flocs through cavitation processes [24]. Sonication destroyed the large flocs formed after sludge treatment using $0.8 \%$ and $1.1 \%$ flocculant, and with $0.7 \%$ SR (Figure $4 \mathrm{~b}$ ). However, sonication did not affect the particle size distribution in sludge treated with $0 \%$ and $0.6 \%$ flocculant, and with $1.1 \%$ SR, which indicates that flocs formed in these sludges were stable compared to flocs formed after other treatments. Overall, flocs could be formed without flocculant or with a small amount of flocculant, and were stable against sonication. Increasing the 
amount of flocculant could contribute to the formation of large flocs; however, the flocs were not stable without sludge recycling. The stability of flocs could be related to dewaterability. Large particles with little strength disintegrate easily and they also show low dewaterability. In contrast, small flocs are hard to destroy [25].
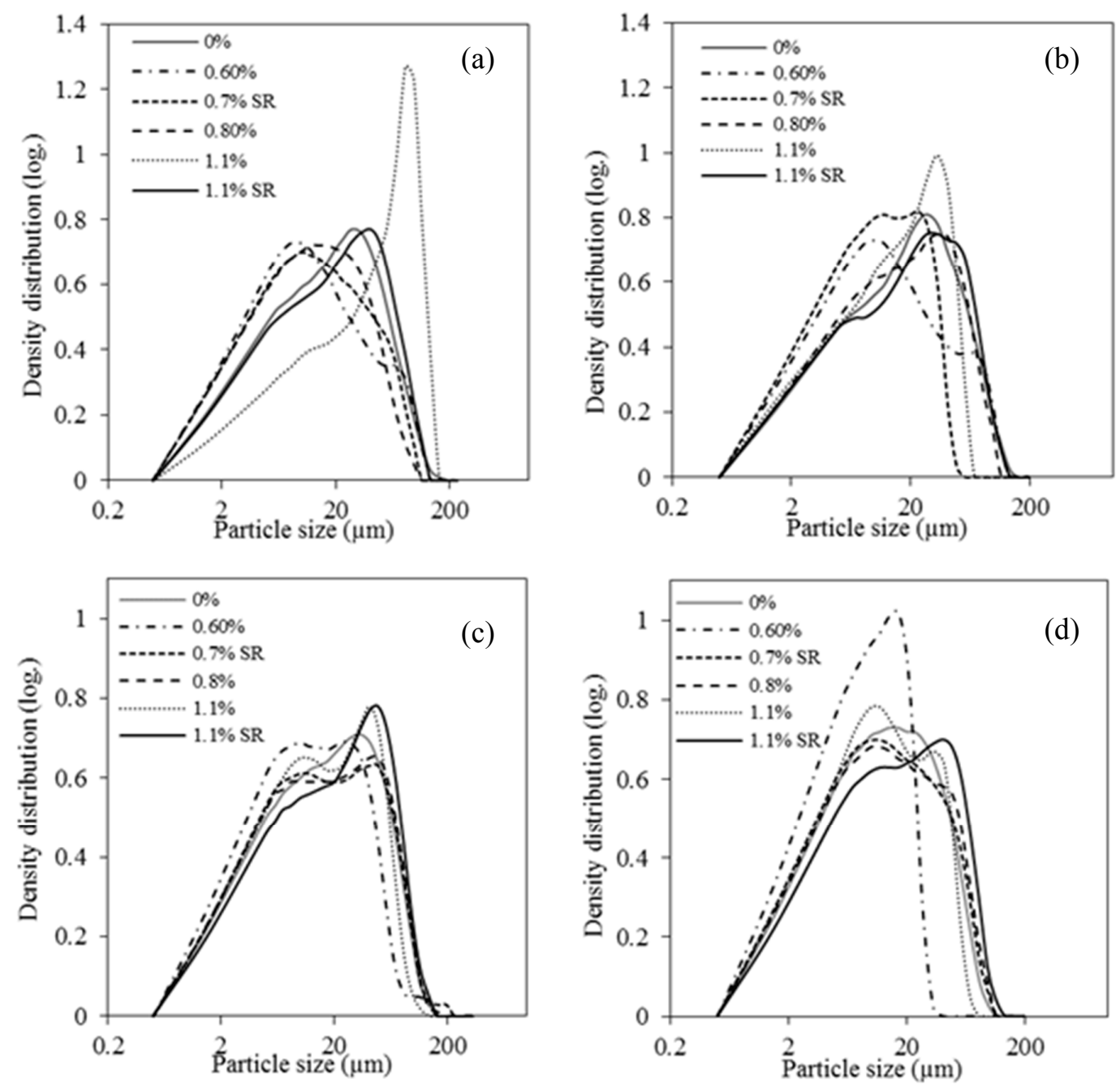

Figure 4. Particle size distribution of flocs in the sludge collected soon after wastewater treatment $(\mathbf{a}, \mathbf{b})$ and after two months of storage (c,d) with different dosage of flocculant and sludge recycling. Here, $(\mathbf{b}, \mathbf{d})$ are particle size distribution after sonication of $(\mathbf{a}, \mathbf{c})$ samples, respectively.

Floc stability was also evaluated by aging the sludge for two months and then analyzing the particle size distribution. After two months of sludge aging, the particle size distribution of the floc shifted to coarser particles except for sludge treated with $0.6 \%$ and $1.1 \%$ flocculant (Figure $4 \mathrm{c}$ ). In particular, treatment with $0.6 \%$ flocculant showed the smallest particle size distribution and the flocs formed were not stable against sonication after aging. Sludge treated with $1.1 \%$ flocculant with sludge recycling $(1.1 \%$ SR) was relatively stable compared to that after other treatments (Figure $4 \mathrm{~d})$. Increase in the proportion of small particles in the sludge treated with $0.6 \%$ flocculant after sonication could be related to increase in the SRF after long-term storage. It was reported that dewaterability decreased when supra-colloidal particles $(1-100 \mu \mathrm{m})$ increased [26].

Although aging of the sludge further enhanced floc formation, increase in the large particle fraction did not contribute to better dewaterability. More influential factors seem to be change in the proportion of finer particles and particle size distribution. After aging, the particle size distribution 
changed from unimodal to bimodal, which might cause increased dewaterability. Dewaterability is related not only to particle size, but also to particle size distribution. The addition of flocculant changes the particle size distribution by combining small particles, and thereby affects dewaterability [27]. Therefore, sludge is better to be dewatered soon after wastewater treatment. Decreased specific surface area of the sludge after addition of flocculant can improve dewaterability because resistance to filtration is related to surface drag losses [28]. Sludge with narrow particle size distribution shows relatively low SRF compared to sludge with wide particle size distribution [29]. Although the mean floc diameter of $0.7 \%$ SR sludge was the smallest, it showed a narrow particle size distribution compared to other treatments, which might have resulted in the smallest SRF.

\section{Conclusions}

Increasing the flocculant dosage did not necessarily lead to enhanced dewaterability although it may improve flocculation rate by formation of large flocs. Instead, sludge recycling with a smaller amount of flocculant enhanced dewaterability because of the resulting narrow particle size distribution. Therefore, for the long-term stability of flocs, less flocculant should be applied and sludge recycling should be performed. The use of smaller amounts of flocculant and improved dewaterability of the sludge should reduce the cost for recycling mineral-processing wastewater, and thus also make it more environmentally sustainable.

Author Contributions: Conceptualization, J.H.P. and S.-W.J.; Methodology, J.H.P. and Y.-S.H.; Software, J.H.P. and Y.-S.H.; Writing-Original Draft Preparation, J.H.P.; Writing-Review \& Editing, Y.-S.H. and S.-W.J.; Visualization, J.H.P.; Supervision, S.-W.J.; Project Administration, S.-W.J.; Funding Acquisition, S.-W.J.

Funding: This research was supported by the National Strategic Project-Carbon Upcycling of the National Research Foundation of Korea (NRF) funded by the Ministry of Science and ICT (MSIT), the Ministry of Environment (ME) and the Ministry of Trade, Industry and Energy (MOTIE). (Grant number 2017M3D8A2085336).

Conflicts of Interest: The authors declare no conflict of interest.

\section{References}

1. Gunson, A.J.; Klein, B.; Veiga, M.; Dunbar, S. Reducing mine water requirements. J. Clean. Prod. 2012, 21, 71-82. [CrossRef]

2. Rubio, J.; Souza, M.L.; Smith, R.W. Overview of flotation as a wastewater treatment technique. Miner. Eng. 2002, 15, 139-155. [CrossRef]

3. Teh, C.Y.; Budiman, P.M.; Shak, K.P.Y.; Wu, T.Y. Recent advancement of coagulation-flocculation and its application in wastewater treatment. Ind. Eng. Chem. Res. 2016, 55, 4363-4389. [CrossRef]

4. Choy, S.Y.; Prasad, K.M.N.; Wu, T.Y.; Raghunandan, M.E.; Ramanan, R.N. Utilization of plant-based natural coagulants as future alternatives towards sustainable water clarification. J. Environ. Sci. 2014, 26, 2178-2189. [CrossRef] [PubMed]

5. Pearse, M.J. Historical use and future development of chemicals for solid-liquid separation in the mineral processing industry. Miner. Eng. 2003, 16, 103-108. [CrossRef]

6. Johnson, P.D.; Girinathannair, P.; Ohlinger, K.N.; Ritchie, S.; Teuber, L.; Kirby, J. Enhanced removal of heavy metals in primary treatment using coagulation and flocculation. Water Environ. Res. 2008, 80, 472-479. [CrossRef] [PubMed]

7. Lee, K.; Lee, D.; Lieu, A. Trace metal removal with precipitated solids from uranium mine effluent at Cameco's Key Lake operation. In Water in Mineral Processing; Drelich, J., Ed.; Society for Mining, Metallurgy, and Exploration, Inc.: Englewood, CO, USA, 2012; ISBN 978-0-87335-349-6.

8. Chen, T.; Xu, Y.; Wang, D.; Shi, W.; Cui, F. The impact of recycling sludge on water quality in coagulation for treating low-turbidity source water. Desalination Water Treat. 2016, 27, 14433-14442. [CrossRef]

9. Dahlstrom, D.A. Liquid-solid separation. In Principles of Mineral Processing; Fuerstenau, M.C., Ed.; Society for Mining, Metallurgy, and Exploration, Inc.: Englewood, IL, USA, 2003; pp. 307-336.

10. Park, J.H.; Oh, C.; Han, Y.S.; Ji, S.W. Optimizing the addition of flocculants for recycling mineral processing wastewater. Geosyst. Eng. 2016, 19, 83-88. [CrossRef] 
11. Weiner, R.F.; Matthews, R. Environmental Engineering; Elsevier Science: Burlington, MA, USA, 2003; pp. 205-222.

12. Ministry of Environment. Enforcement Decree of the Water Quality and Aquatic Ecosystem Conservation Act; Ministry of Government Legislation: Seoul, Korea, 2018.

13. Dash, M.; Dwari, R.K.; Biswal, S.K.; Reddy, P.S.R.; Chattopadhyay, P.; Mishra, B.K. Studies on the effect of flocculant adsorption on the dewatering of iron ore tailings. Chem. Eng. J. 2011, 173, 318-325. [CrossRef]

14. Ofir, E.; Oren, Y.; Adin, A. Electroflocculation: The effect of zeta-potential on particle size. Desalination 2007, 204, 33-38. [CrossRef]

15. Clogston, J.D.; Patri, A.K. Zeta potential measurement. In Characterization of Nanoparticles Intended for Drug Delivery; McNeil, S.E., Ed.; Humana Press: New York, NY, USA, 2011; pp. 63-70.

16. Yu, J.; Wang, D.; Ge, X.; Yan, M.; Yang, M. Flocculation of kaolin particles by two typical polyelectrolytes: A comparative study on the kinetics and floc structures. Colloids Surf. Physicochem. Eng. Asp. 2006, 290, 288-294. [CrossRef]

17. Li, X.Y.; Yang, S.F. Influence of loosely bound extracellular polymeric substances (EPS) on the flocculation, sedimentation and dewaterability of activated sludge. Water Res. 2007, 41, 1022-1030. [CrossRef] [PubMed]

18. Jin, B.; Wilén, B.M.; Lant, P. Impacts of morphological, physical and chemical properties of sludge flocs on dewaterability of activated sludge. Chem. Eng. J. 2004, 98, 115-126. [CrossRef]

19. Wilén, B.M.; Jin, B.; Lant, P. Impacts of structural characteristics on activated sludge floc stability. Water Res. 2003, 37, 3632-3645. [CrossRef]

20. Neyens, E.; Baeyens, J. A review of thermal sludge pre-treatment processes to improve dewaterability. J. Hazard. Mater. 2003, 98, 51-67. [CrossRef]

21. Yuan, H.; Zhu, N.; Song, F. Dewaterability characteristics of sludge conditioned with surfactants pretreatment by electrolysis. Bioresour. Technol. 2011, 102, 2308-2315. [CrossRef] [PubMed]

22. Liss, S.N.; Liao, B.Q.; Droppo, I.G.; Allen, D.G.; Leppard, G.G. Effect of solids retention time on floc structure. Water Sci. Technol. 2002, 46, 431-438. [CrossRef] [PubMed]

23. Pollice, A.; Laera, G.; Saturno, D.; Giordano, C. Effects of sludge retention time on the performance of a membrane bioreactor treating municipal sewage. J. Membr. Sci. 2008, 317, 65-70. [CrossRef]

24. Biggs, C.A.; Lant, P.A. Activated sludge flocculation: On-line determination of floc size and the effect of shear. Water Res. 2000, 34, 2542-2550. [CrossRef]

25. Fitria, D.; Scholz, M.; Swift, G.M.; Hutchinson, S.M. Impact of sludge floc size and water composition on dewaterability. Chem. Eng. Technol. 2014, 37, 471-477. [CrossRef]

26. Higgins, M.J.; Novak, J.T. Dewatering and settling of activated sludges: The case for using cation analysis. Water Environ. Res. 1997, 69, 225-232. [CrossRef]

27. Neyens, E.; Baeyens, J.; Dewil, R. Advanced sludge treatment affects extracellular polymeric substances to improve activated sludge dewatering. J. Hazard. Mater. 2004, 106, 83-92. [CrossRef] [PubMed]

28. Turchiuli, C.; Fargues, C. Influence of structural properties of alum and ferric flocs on sludge dewaterability. Chem. Eng. J. 2004, 103, 123-131. [CrossRef]

29. Su, X.; Tian, Y.; Li, H.; Wang, C. New insights into membrane fouling based on characterization of cake sludge and bulk sludge: An especial attention to sludge aggregation. Bioresour. Technol. 2013, 128, 586-592. [CrossRef] [PubMed]

(C) 2018 by the authors. Licensee MDPI, Basel, Switzerland. This article is an open access article distributed under the terms and conditions of the Creative Commons Attribution (CC BY) license (http://creativecommons.org/licenses/by/4.0/). 